polypharmacy in a patient group that is often non-responsive to medication and usually has complex comorbidities.

Furthermore, we would dispute the notion that Taylor suggested: that non-medical prescribers may improve the situation. We have concerns which are rather in contrast to this. Non-medical prescribers are more likely to follow guidance but if guidance changes or is flawed, as we have seen with the NICE guidelines for schizophrenia, non-medical prescribers are more likely to lack the flexibility to respond adequately to these challenges and may therefore contribute to suboptimal treatment rather than improve it. Lastly, we wholeheartedly embrace the recommendations that Langen \& Shajahan put forward, ${ }^{2}$ which ask for the regular review of all instances of polypharmacy including clear documentation as to why polypharmacy is continuously used.

1 Taylor D. Antipsychotic polypharmacy - confusion reigns. Psychiatrist 2010; 34: 41-3.

2 Langan J, Shajahan P. Antipsychotic polypharmacy: review of mechanisms, mortality and management. Psychiatrist 2010; 34: 58-62.

3 Fleischhacker WW, Heikkinen T, Olie JP, Landsberg W, Dewaele P, McQuade RD, et al. Weight change on aripiprazole-clozapine combination in schizophrenic patients with weight gain and suboptimal response on clozapine: 16 week double-blind study. Eur Psychiatry 2008; 2: s114-5.

4 Tungaraza TE, Gupta S, Jones J, Poole R, Slegg G. Polypharmacy and high-dose antipsychotic regimes in the community. Psychiatrist 2010; 34: $44-6$.

5 Achim AM, Maziade M, Raymond E, Olivier D, Mérette C, Roy MA. How prevalent are anxiety disorders in schizophrenia? A meta-analysis and critical review on a significant association. Schizophr Bull $2009 \mathrm{Dec}$ 3 [epub ahead of print], doi: 10.1093/schbul/sbp148

6 Dernovsek MZ, Sprah L. Comorbid anxiety in patients with psychosis. Psychiatr Danub 2009; 21 (suppl 1): 43-50.

7 Sharma VK, Lepping P, Cummins AG, Copeland JR, Parhee R, Mottram P. The Global Mental Health Assessment Tool - Primary Care Version (GMHAT/PC). Development, reliability and validity. World Psychiatry 2004; 3: 115-9.

8 Mortimer AM. Update on the management of symptoms in schizophrenia: focus on amisulpride. Neuropsychiatr Dis Treat 2009; 5: 267-77.

9 Leucht S, Corves C, Arbter D, Engel RR, Li C, Davis JM. Secondgeneration versus first-generation antipsychotic drugs for schizophrenia: a meta-analysis. Lancet 2009; 373: 31-41.

10 Karunakaran K, Tungaraza TE, Harborne GC. Is clozapine-aripiprazole combination a useful regime in the management of treatment-resistant schizophrenia? J Psychopharmacol 2007; 21: 453-6.

Peter Lepping Consultant Psychiatrist, Honorary Senior Lecturer and Associate Medical Director; Giles C. Harborne Consultant Psychiatrist and Chief of Staff Mental Health, Betsi Cadwaladr University Health Board, Wrexham, UK. Email: peter.lepping@wales.nhs.uk

doi: 10.1192/pb.34.5.208

\section{Let's not throw the baby out with the bath water}

Tyrer et al's study on the effectiveness of crisis resolution and home treatment teams (CRHTs) is a good addition to the debate on the evidence base of these teams. The authors concluded that the introduction of CRHTs in Cardiff was associated with an increase in compulsory admission, a decrease in informal admission and bed days, and an increase in the number of suicides in the area covered by CRHTs. In as much as the authors can be commended in their fairly robust appraisal of the research methodology employed, nonetheless it is hard to overlook the major deficiencies in the study design.
The findings, but for the increased rate of suicides, are not new, and need not reflect negatively on CRHTs. The authors highlighted that none of the victims of suicide were under the care of the CRHT at the time of their death.

The often-cited North Islington Study ${ }^{2}$ also showed that compulsory admission was not significantly reduced; however in recent years a number of possible explanations for this finding have emerged. It is highly likely that a sizeable proportion of the patients who were compulsorily admitted were not only severely ill, but lacking in insight or capacity to consent to a treatment plan. Gould et al's ${ }^{3}$ study on patients presenting with acute onset of first-episode psychosis concluded that in this group of patients, although living in an area in which alternatives to admission were well developed, compulsory admission was still high.

Crisis resolution and home treatment teams exist within complex local systems and politics and it is inevitable that other key services such as the traditional community mental health team, in-patient service, mental health liaison team, primary care gateway service, assertive outreach and early intervention team in psychosis will play key roles in its effectiveness. An interesting enquiry is whether such specialist teams working jointly with CRHTs will be able to prevent compulsory in-patient admissions for these severely ill patients more effectively than CRHT alone.

A Cochrane review ${ }^{4}$ continues to gather increasing longterm evidence to support the implementation of the CRHT worldwide. The evidence for reducing informal admission, bed usage and patient satisfaction has been replicated in various studies. Crisis resolution and home treatment teams should not be seen as a government-enforced innovation, but rather a viable and acceptable approach to treating people with severe mental illness. Evidence suggests that improvements in outcome of $\mathrm{CRHTs}$ are most convincing where psychiatrists have embraced this development and use their informal power to support them. ${ }^{5}$ Let's not throw the baby out with the bath water.

1 Tyrer P, Gordon F, Nourmand S, Lawrence M, Curran C, Southgate D, et al. Controlled comparison of two crisis resolution and home treatment teams. Psychiatrist 2010; 34: 50-4.

2 Johnson S, Nolan F, Pilling S, Sandor A, Hoult J, McKenzie N, et al. Randomised controlled trial of acute mental health care by a crisis resolution team: the north Islington crisis study. BMJ 2005; 331 599-602.

3 Gould M, Theodore K, Pilling S, Bebbington P, Hinton M, Johnson S. Initial treatment phase in early psychosis: can intensive home treatment prevent admission? Psychiatr Bull 2005; 30: 243-6.

4 Irving CB, Adams CE, Rice K. Crisis intervention for people with severe mental illness. Cochrane Database Syst Rev 2006; 4: CD001087.

5 Middleton $\mathrm{H}$, Glover $\mathrm{G}$, Onyett $\mathrm{S}$, Linde K. Crisis resolution/home treatment teams, gate-keeping and the role of the consultant psychiatrist. Psychiatr Bull 2008; 32: 378-9.

Stephen Ogunremi is Locum Consultant Psychiatrist, Portsmouth City Teaching Hospital, email: Stephen.Ogunremi@ports.nhs.uk; Bilal Talat is Locum Staff Grade Psychiatrist, Portsmouth City Teaching Hospital.

doi: $10.1192 / \mathrm{pb} .34 .5 .209$

\section{Confusing title and misleading assumptions}

The title and the aim of the study by Tyrer et al state that they had made a controlled comparison of two crisis resolution and home treatment teams (CRHTs). However, reading through the 
article the data-set they looked at applies only to one CRHT. The second CRHT was not in existence in the two time periods when the data were collected.

There are inaccuracies in the reporting; in the results section the authors report duration of bed use and refer to Table 2 which is occupied bed days. The duration of bed use and number of bed days are two different measures. Also, numbers do not add up in Table 2, however they do add up in Table 1.

In summary, the study reports no statistically significant difference in number of admissions or number of bed days following introduction of a CRHT when compared with an area without the team. However, raw figures demonstrate a decrease in informal admissions and bed days, and an increase in formal admissions in the area where there is a crisis team.

The authors make assumptions that the increase in compulsory admissions following the introduction of a CRHT was because some patients who would otherwise have been admitted to the hospital and then detained under Section 5(2) of the Mental Health Act were taken on by the CRHT and then getting admitted through mental health assessments and on a section. This assumption is not supported by the data-set or anecdotal evidence.

The study also found that there is an increase in suicide in the catchment area where there is a CRHT. However, none of these suicides happened when the patients were under the CRHT. As it stands, it is difficult to explain that the increase in suicide is somehow connected to the introduction of the CRHT.

It is safe to assume that in Cardiff as the experience of the team grows and the teams get more embedded they will have a significant effect on both number of admissions and bed usage as demonstrated by the National Audit Office report. ${ }^{2}$

1 Tyrer P, Gordon F, Nourmand S, Lawrence M, Curran C, Southgate D, et al. Controlled comparison of two crisis resolution and home treatment teams. Psychiatrist 2010; 34: 50-4

2 National Audit Office. Helping People through Mental Health Crisis: The Role of Crisis Resolution and Home Treatment Services. TSO (The Stationery Office), 2007.

Prem N. Mahadun, Consultant Psychiatrist, Greater Manchester West Mental Health NHS Foundation Trust, email: prem.mahadun@ trafford.nhs.uk; Khurram Sadiq, staff grade doctor, Greater Manchester West Mental Health NHS Foundation Trust, UK.

doi: $10.1192 /$ pb.34.5.209a

Authors' reply Dr Mahadun \& Sadiq are right on both counts. The title 'A controlled comparison of the introduction of a crisis resolution and home treatment team' should be the proper title of the article. The top two lines of data in Table 2 are also incorrect, and should read as shown here.

These data illustrate an effect of the crisis resolution team (CRT) overall in reducing bed days. We agree that the interpretation of the data cannot provide a causal pathway between the experience of seeing a CRT and then having a higher risk of being admitted compulsorily, as we were not following the experience of individual patients through the care system. However, it is a reasonable hypothesis to posit that the increase in compulsory admissions following the introduction of the CRT was a direct consequence of the change in service provision across the trust. The same conclusion might be made about the change in suicide rates, but of course we stress that this was not a significant difference. The conclusion we are
Table Number of bed days occupied in two 9-month study periods before and after the introduction of a crisis resolution (CRT) team

\begin{tabular}{lccc}
$\begin{array}{l}\text { Patient } \\
\text { status }\end{array}$ & Team & $\begin{array}{c}\text { CRT service } \\
\text { (number }\end{array}$ & $\begin{array}{c}\text { Control service } \\
\text { (number }\end{array}$ \\
\hline Total & Pre-CRT & $6133(74.2)$ & $15525(72.4)$ \\
& Post-CRT & $5542(67.1)$ & $15352(71.6)$
\end{tabular}

putting forward, and this was not one we were expecting when we started the study, is that the service configuration that follows the introduction of a CRT is one that tends to limit admissions and may possibly be directly associated with more compulsory admissions and more suicides. This is an important hypothesis to test, but we agree it cannot be confirmed from our data.

Drs Ogunremi \& Talat argue from the position of enthusiasts for the CRT policy and we do not disagree with their opinion that it is a 'viable and acceptable approach to treating people with severe mental illness'. But all policies have to be tested and evaluated, and clearly all your correspondents would agree that if a CRT, for whatever reasons, makes decisions that lead to greater compulsion and more suicides in either the shorter or longer term, their implementation should be questioned. In this context it could also be argued that a reduction in bed usage is probably a poor outcome measure; quality of life, patient satisfaction and clinical improvement over a reasonable period (e.g. probably about a year to cover all aspects of an illness episode) are much preferred.

\section{Declaration of interest}

J.M. is currently a consultant in one of the Cardiff crisis resolution teams.

Peter Tyrer, Professor of Community Psychiatry, Imperial College London, email: p.tyrer@imperial.ac.uk. Janice Morgan, Consultant Psychiatrist, Pendine Centre, Cardiff. Bernard North, statistician, Statistical Advisory Service, Imperial College London, UK

doi: $10.1192 / p b \cdot 34.5 .210$

\section{Improving physical health monitoring in psychiatry - change we need?}

Gonzalez et al highlight the very important issue of routine blood testing of patients on antipsychotics, which currently is under-monitored in a psychiatric setting, particularly so in outpatients. However, the audit was conducted between 2004 and 2005, and it might not represent the current practice in UK. But physical health monitoring of patients with mental health problems still remains unsatisfactory. Some studies in 1986 and 2004 reported recording of physical examination carried out on admission by psychiatric trainees to be 'uniformly poor' to 'variable'. 'The age-adjusted annual death rates from all causes among individuals with a psychiatric diagnosis is two to four times higher than in the general population. ${ }^{3}$ This makes it even more pertinent for us to take extra measures in order to provide the best care for our patients. 